\title{
Sonographic evaluation of diaphragmatic thickness and excursion as a predictor for successful extubation in mechanically ventilated preterm infants
}

\author{
Eslam Bahgat ${ }^{1} \cdot$ Hanan El-Halaby ${ }^{2} \cdot$ Ashraf Abdelrahman $^{3} \cdot$ Nehad Nasef $^{1,2,4}(\mathbb{D}) \cdot$ Hesham Abdel-Hady ${ }^{1,2}$
}

Received: 5 July 2020 / Revised: 22 August 2020 / Accepted: 8 September 2020 / Published online: 28 September 2020

(C) Springer-Verlag GmbH Germany, part of Springer Nature 2020

\begin{abstract}
Sonographic assessment of diaphragmatic thickness and excursion has been found to be an accurate tool in predicting successful extubation of adult patients from invasive mechanical ventilation. We aimed to evaluate the accuracy of sonographic assessment of diaphragmatic thickness and excursion in predicting successful extubation of preterm infants from invasive conventional mechanical ventilation. Preterm infants less than 32 weeks gestation who required invasive conventional mechanical ventilation were evaluated by diaphragmatic sonography within $1 \mathrm{~h}$ of their planned extubation. Infants were classified into successful or failed extubation groups based on their ability to stay off invasive mechanical ventilation for $72 \mathrm{~h}$ after extubation. Inspiratory and expiratory thickness plus excursion of the right and left hemidiaphragm as well as diaphragmatic thickening fraction (DTF) measures were compared between groups. We included 43 eligible infants, of whom 34 infants succeeded and 9 infants failed extubation. Infants in the successful extubation group had a significantly higher expiratory thickness of the right and left hemidiaphragm, excursion of the right and left hemidiaphragm, inspiratory thickness of the left hemidiaphragm, and DTF of the left hemidiaphragm compared with infants who failed extubation. The receiver-operating characteristic curves showed that excursion of the right and left hemidiaphragm has the highest significant accuracy in predicting successful extubation of preterm infants among all diaphragmatic parameters (AUC is 0.98 and 0.96 , respectively; $p$ value $<0.001$ for both).

Conclusion: We conclude that diaphragmatic excursion is a useful indicator for successful extubation of preterm infants from mechanical ventilation.
\end{abstract}

What is Known:

- Invasive mechanical ventilation induces ventilator induced diaphragmatic dysfunction (VIDD) particularly when used for long time.

- Assessment of diaphragmatic dimensions and functional activity has been a valuable tool in predicting successful extubation of adult patients from invasive mechanical ventilation.

What is New:

- Sonographic assessment of diaphragmatic dimensions can be used to predict successful extubation of preterm infants from mechanical ventilation.

- Sonographic assessment of diaphragmatic excursion shows the highest sensitivity and specificity in predicting successful extubation of preterm infants.

Communicated by Daniele De Luca

Nehad Nasef

nehad_nasef@mans.edu.eg

Eslam Bahgat

dr_eslam_1986@yahoo.com

Hanan El-Halaby

hanan_elhalaby@yahoo.com

Ashraf Abdelrahman

ashrafmuhamed2@gmail.com

Hesham Abdel-Hady

heshhady@mans.edu.eg
1 Neonatal Intensive Care Unit, Mansoura University Children's Hospital, Mansoura, Egypt

2 Department of Pediatrics, Faculty of Medicine, University of Mansoura, Mansoura, Egypt

3 Department of Diagnostic Radiology, Mansoura University Children's Hospital, Mansoura, Egypt

4 Department of Pediatrics, Mansoura University Children's Hospital, Gomhoria Street, Mansoura 35516, Egypt 
Keywords Preterm infant $\cdot$ Mechanical ventilation $\cdot$ Extubation predictor $\cdot$ Ultrasound waves $\cdot$ Diaphragm

\author{
Abbreviations \\ AUC Area under the curve \\ CPAP Continuous positive airway pressure \\ DTF Diaphragmatic thickening fraction \\ NICU Neonatal intensive care unit \\ VIDD Ventilator induced diaphragmatic dysfunction \\ $\mathrm{FiO}_{2} \quad$ Fraction of inspired oxygen
}

\section{Introduction}

The decision to extubate preterm infants from mechanical ventilators is mainly based on clinical assessment, blood gases, and ventilator settings [7]. Researchers attempted to evaluate different parameters as predictors for successful extubation of preterm infants from mechanical ventilation $[26,28]$. However, up to $30 \%$ of preterm infants who are extubated based on the clinical assessment require reintubation indicating a poor correlation with infants' readiness for extubation [3, 28].

The diaphragm represents the main respiratory muscle in infancy. It contributes to generation of an estimated threefourths of the infant's tidal volume during resting inspiration in the supine position [23]. Continuous positive airway pressure (CPAP) affects the crura of diaphragm by shortening the muscle and decreasing excursion through maintaining end expiratory lung volume [21]. Moreover, prolonged mechanical ventilation triggers myofibrillar contractile dysfunction and myofilament protein loss of the diaphragmatic muscles which later results in loss of diaphragmatic force-generating capacity, poor activity, and unloading of the diaphragm [10]. This phenomenon of ventilator-induced diaphragmatic dysfunction (VIDD) has raised the attention of investigators to the correlation between duration of mechanical ventilation and failure to extubate preterm infants from mechanical ventilation [27]. However, the diagnosis of this diaphragmatic dysfunction can be hindered by the lack of appropriate quantitative assessments of neonatal diaphragm function [1].

Accurate assessment of diaphragm function in the neonate could aid to the diagnosis of respiratory distress, evaluation of therapeutic interventions, and identification of infants ready to wean from mechanical ventilation [20]. Monitoring the electrical activity of the diaphragm in infants and children has shown that higher diaphragmatic activity in relation to tidal volume indicates a better preserved diaphragmatic function and a better chance of passing the extubation readiness test [29]. However, the tools needed for monitoring the electrical activity of the diaphragm are invasive, expensive, and require trained personnel for proper interpretation. Sonographic evaluation of the diaphragm is ubiquitous in medical facilities, requires no radiation, can be used at the infant's bedside, and useful in assessing diaphragmatic mobility and excursion [13].

We hypothesized that assessment of diaphragmatic dimensions and excursion, before planned extubation, may be helpful in predicting successful extubation of preterm infants from mechanical ventilation. We aimed to study sonographic assessment of the diaphragmatic dimensions and excursion for mechanically ventilated preterm infants as a predictor for success of extubation.

\section{Methods}

The present study was placed at the Neonatal Intensive Care Unit (NICU) of Mansoura University Children's Hospital, Mansoura, Egypt, between January 2017 and November 2019. The study was approved by the Institutional Review Board, Mansoura Faculty of Medicine, and a fully informed written consent was obtained from the parent or infant's guardian before enrolment in the study.

\section{Study designs}

This was a prospective, observational, cohort study assessing diaphragmatic thickness and excursion for preterm infants prior to planned extubation from invasive conventional mechanical ventilation.

\section{Participants}

Preterm infants less than 32 weeks gestation who were supported by invasive conventional mechanical ventilation for a diagnosis of respiratory distress syndrome, as evident by clinical and radiological findings, and planned for extubation were eligible for this study. Preterm infants with chromosomal aberrations, hepatosplenomegaly, pleural effusion, congenital heart or lung disorders, or congenital anomalies related to diaphragm as diaphragmatic hernia and diaphragmatic paralysis were excluded from the study.

\section{Intervention}

Eligible preterm infants had sonographic assessment of diaphragmatic thickness and excursion within $1 \mathrm{~h}$ of planned extubation from invasive conventional mechanical ventilation to non-invasive respiratory support. Preterm infants were extubated from mechanical ventilation if they fulfilled the following criteria: spontaneous respiratory effort, presence of cough or gag induced by suctioning, acceptable arterial blood 
gases ( $\mathrm{pH}$ more than 7.25, $\mathrm{PaCO}_{2}$ less than $60 \mathrm{mmHg}$, and base deficit less than $8 \mathrm{mEq} / \mathrm{L}$ ) on a mean airway pressure less than $8 \mathrm{~cm} \mathrm{H}_{2} \mathrm{O}$ and respiratory rate of less than $30 / \mathrm{min}$, saturation more than $90 \%$ on fraction of inspired oxygen $\left(\mathrm{FiO}_{2}\right)$ less than $30 \%$ in the preceding $24 \mathrm{~h}$, and the decision of extubation was taken by the attending physician who was blinded to the results of sonographic measurements.

Sonographic diaphragmatic parameters were measured while infants were on spontaneous pressure support ventilation mode with a support pressure of $4 \mathrm{~cm} \mathrm{H}_{2} \mathrm{O}$ over an end expiratory pressure of $4 \mathrm{~cm} \mathrm{H}_{2} \mathrm{O}$ for $1 \mathrm{~h}$ prior to the sonographic assessment as an accommodation. The total duration on pressure support ventilation mode and sonographic diaphragmatic assessment was $2 \mathrm{~h}$ at most to avoid infant exhaustion. Sonographic evaluation was performed prior to the time of next feed, while infant's stomach is empty, to avert any interference of a full stomach on diaphragmatic mobility and measurements. All infants were extubated to nasal CPAP using the Infant Nasal CPAP Assembly system (Fisher \& Paykel Healthcare, Auckland, New Zealand) at a pressure of $5 \mathrm{cmH}_{2} \mathrm{O}$ and $\mathrm{FiO}_{2}$ between $21 \%$ and $30 \%$ to keep infant's saturation between $90 \%$ and $95 \%$.

\section{Sonographic diaphragmatic assessment technique}

Ultrasonographic examinations were performed by one operator, who had ten years of experience in diaphragm sonography, using a portable Doppler ultrasonography (Micro-Maxx; SonoSite, Bothell, WA, USA) with a micro-convex transducer array (10 to $5 \mathrm{MHz}$ ). Diaphragmatic sonography was performed while the infant is in supine position after ensuring quiet regular breathing. For visualization of the right hemidiaphragm, the convex probe was placed over the right subcostal and lower intercostal spaces between the anterior axillary and the midclavicular lines with the probe directed cranially, dorsally, and medially so the radial beam came to be perpendicular to the posterior third of the right hemidiaphragm. For visualization of the left hemidiaphragm, the same technique, position, and direction of the probe as the right hemidiaphragm were performed apart from the probe was placed between the left anterior axillary and midaxillary lines.

At first, the two-dimensional mode was screened to detect the appropriate exploration image for each hemidiaphragm in which the diaphragm appeared as a hypoechoic line that was placed between two echogenic lines, the upper one was the reflection of the parietal pleura and the lower was for the peritoneum. After that, the M-mode ultrasonography was screened and the image was frozen after ensuring regular up and down movement of the diaphragmatic line that reflects regular breathing. The thickness of the diaphragmatic line during inspiration (upward slope) and expiration (downward slope) represents the diaphragmatic inspiratory and expiratory thickness, respectively. The perpendicular distance between the most caudal point of this line during inspiration and the most caudal point during expiration represents the diaphragmatic excursion. Diaphragmatic thickness and kinetics measures can be affected by the irregular breathing pattern, high respiratory rate, breath to breath variability, and small diaphragmatic dimensions by using M-mode technique in preterm infants. To overcome this technical limitation, the investigator observed for regular up and down movements of the diaphragmatic line in M-mode and cine for $1 \mathrm{~min}$ to ensure an epoch of quiet regular breathing, and then diaphragmatic measurements were obtained [2]. The technique and measurements were repeated up to 3 respiratory cycles for each hemidiaphragm, and the average one was recorded [5]. Avoidance of diaphragmatic measurements during infant's crying or sighing movement was taken in consideration.

The diaphragmatic thickening fraction (DTF) was calculated and recorded using the following formula: DTF $=[$ (inspiratory thickness - expiratory thickness) / expiratory thickness] $\times 100[8]$.

The intra-observer reproducibility was evaluated by repeated measurements of sonographic diaphragmatic parameters by the same investigator with $30 \mathrm{~min}$ in between measurements. Ten clinically stable preterm infants, age and sex cross-matched with the studied group, were randomly selected for this purpose.

\section{Study end point}

The primary study end point was successful extubation from invasive mechanical ventilation defined as being off mechanical ventilation with transmission to oxygen therapy or noninvasive respiratory support, for at least $72 \mathrm{~h}$ post-extubation [12]. The indications for re-intubation were specified as follows: more than six episodes of apnea requiring stimulation within $6 \mathrm{~h}$, or more than one significant episode of apnea requiring bag and mask ventilation, respiratory acidosis $\left(\mathrm{PaCO}_{2}>65 \mathrm{mmHg}\right.$ and $\left.\mathrm{pH}<7.25\right)$ or $\mathrm{FiO}_{2}>60 \%$ to maintain saturation in the target range (90-95\%) [12].

\section{Sample size calculation}

Sample size calculation was based on the area under the receiver-operating characteristic curve that was 0.79 for predicting successful extubation of mechanical ventilation retrieved from previous research [4]. Using MedCalc for Windows, version 15.0 (MedCalc Software, Ostend, Belgium), sample size calculation using area under ROC curves with null hypothesis $=0.5, \alpha$-error $=0.05$, power of the study $=80 \%$ ratio of positive to negative cases which will be considered as 3.3. The total calculated sample size will be 43 cases. 


\section{Statistical analysis}

Statistical analysis was performed using SPSS statistical software (version 21; IBM Corporation, Armonk, NY, USA). Student's $t$ test was used to compare continuous parametric variables. Mann-Whitney $U$ test was used for continuous nonparametric variables. Chi-square test or Fisher's exact test was used for categorical variables when appropriate. ShapiroWilk test was done to examine the distribution of data. Pearson's correlation coefficient test was used to correlate between duration of invasive mechanical ventilation and different diaphragmatic measures. The accuracy of different diaphragmatic measurements for predicting successful extubation from invasive mechanical ventilation was evaluated using receiver-operating characteristic (ROC) curves. A $p$ value of $<0.05$ is considered to be statistically significant. Data are expressed as mean \pm standard deviation, median (inter-quartile range), or number (percentage) unless otherwise stated. Reproducibility of the diaphragmatic measurements was assessed by Bland-Altman analysis and Pearson's correlation coefficient.

\section{Results}

Of the 164 preterm infants who were at less than 32 weeks gestation admitted to our NICU during the study period, 62 infants required invasive conventional mechanical ventilation, 43 were included in the study, and 19 were excluded due to various causes (Fig. 1). A total of 34 infants succeeded and 9 infants failed extubation. Infants in the failed extubation group had significantly higher postnatal age at extubation, longer duration of invasive mechanical ventilation, higher preextubation mean airway pressure, and higher pre-extubation $\mathrm{FIO}_{2}$ compared with infants in the successful extubation group (Table 1). Of the 9 infants who failed extubation, 6 infants were reintubated for increased work of breathing in association with hypoxia, two infants were reintubated for increased work of breathing in association with hypercapnia, and one infant was reintubated for apnea which was preceded by increased work of breathing. The mean time for reintubation was $43.5 \pm 13.5 \mathrm{~h}$ with a minimum of 29 and a maximum of $66 \mathrm{~h}$, respectively. Measurements were highly reproducible with a high degree of agreement between diaphragmatic dimensions as assessed by Pearson's correlation coefficient and Bland-Altman analysis. Pearson's correlation coefficient values were above 0.9 , and $p$ values were $<0.001$ for all measured diaphragmatic indices.

Infants in the successful extubation group had a significantly higher expiratory thickness of the right and left hemidiaphragm, excursion of the right and left hemidiaphragm, inspiratory thickness of the left hemidiaphragm, and DTF of the left hemidiaphragm compared with infants who failed extubation to nasal CPAP (Table 2) (Fig. 2). The duration of invasive mechanical ventilation had a significant negative correlation with inspiratory and expiratory thickness of the right and left hemidiaphragm, excursion of the right hemidiaphragm, and DTF of the right and left hemidiaphragm (Table 3).

The ROC curves showed that expiratory thickness of the right and left hemidiaphragm, excursion of the right and left hemidiaphragm, inspiratory thickness of the left hemidiaphragm, and DTF of the left hemidiaphragm had significant accuracies in predicting successful extubation of preterm infants (Fig. 3). Excursion of the right and left hemidiaphragm showed the highest accuracy among all diaphragmatic parameters. A right hemidiaphragmatic excursion of $2.75 \mathrm{~mm}$ was associated with $94 \%$ sensitivity and $89 \%$ specificity in predicting successful extubation. A left hemidiaphragmatic excursion of $2.45 \mathrm{~mm}$ was associated with $94 \%$ sensitivity and $89 \%$ specificity in predicting successful extubation.

\section{Discussion}

Sonographic assessment of the lungs and diaphragm has gained the interest of neonatologists nowadays. Sonographic assessment of the lungs has shown a high sensitivity and specificity in diagnosing various respiratory disorders in neonates [24]. Ultrasound has been recently used to assess diaphragmatic thickness and excursion of diaphragmatic dome in stable spontaneously breathing infants [5]. We aimed to assess the accuracy of sonographic assessment of diaphragmatic thickness and excursion as a predictor for successful extubation of preterm infant from invasive conventional mechanical ventilation. The main finding of our study is that excursion of the right and left hemidiaphragm has the highest accuracy in predicting successful extubation of mechanically ventilated preterm infants. Diaphragmatic excursion was significantly higher in preterm infants successfully extubated from invasive conventional mechanical ventilation compared with infants who failed extubation.

Diaphragmatic activity as a predictor for successful extubation was evaluated in pediatric age group through monitoring of diaphragmatic electrical activity. Assessment of diaphragmatic electrical activity has shown that infants and children who generated higher diaphragmatic activity in relation to tidal volume had a better chance of passing the extubation readiness test as opposed to infants and children who generated lower diaphragmatic activity in relation to tidal volume [29]. Authors in this study stated that diaphragmatic activity in relation to tidal volume indicates a better preserved diaphragmatic function [29].

To the best of our knowledge, this study is the earliest to report the accuracy of assessing diaphragmatic activity by using diaphragmatic ultrasound in prediction of successful 
Fig. 1 Diagram showing the flow of participants in the study

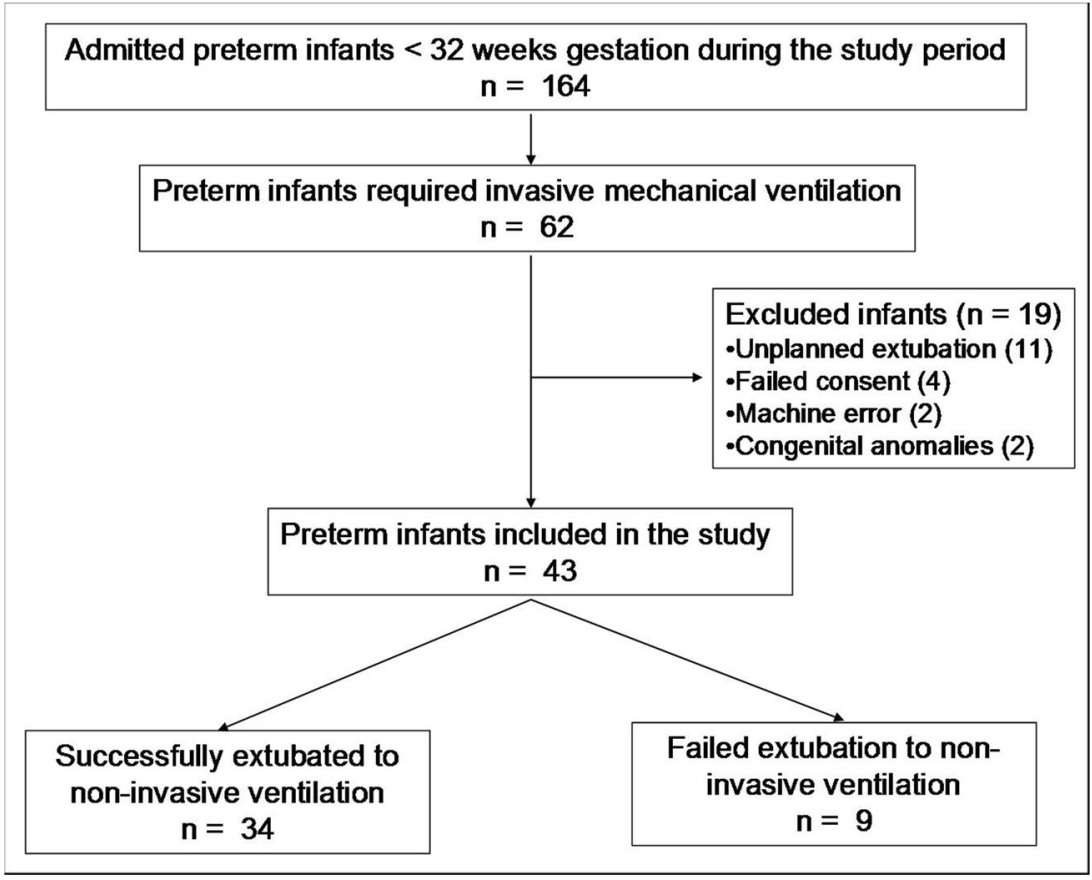

extubation in preterm infants. Over 400 participants between 1 month and 16 years, sonographic assessment of the diaphragm has shown a high accuracy in assessing diaphragmatic thickness and excursion [5]. Rehan and colleagues reported normal diaphragmatic excursion in 34 preterm infants between 26 and 37 weeks gestation to be $5.5 \pm 0.2 \mathrm{~mm}$ at 26
Table 1 Baseline characteristics of the studied groups

\begin{tabular}{|c|c|c|c|}
\hline Characteristics & $\begin{array}{l}\text { Successful extubation } \\
\text { group } \\
(n=34)\end{array}$ & $\begin{array}{l}\text { Failed extubation } \\
\text { group } \\
(n=9)\end{array}$ & $\begin{array}{l}p \\
\text { value }\end{array}$ \\
\hline Gestational age (weeks) & $29.5 \pm 1.7$ & $29.2 \pm 1.7$ & 0.66 \\
\hline Birth weight $(\mathrm{g})$ & $1206 \pm 249$ & $1111 \pm 123$ & 0.28 \\
\hline Male sex & $10(29 \%)$ & $3(33 \%)$ & 0.98 \\
\hline \multicolumn{4}{|l|}{ Apgar score } \\
\hline - $1 \mathrm{~min}$ & $5(3-6)$ & $4(4-6)$ & 0.62 \\
\hline - $5 \mathrm{~min}$ & $8(6-9)$ & $8(7-8)$ & 0.86 \\
\hline \multicolumn{4}{|l|}{ Mode of delivery } \\
\hline $\begin{array}{l}\text { - Vaginal delivery } \\
\text { - Cesarean section }\end{array}$ & $\begin{array}{l}9(26 \%) \\
25(74 \%)\end{array}$ & $\begin{array}{l}4(44 \%) \\
5(56 \%)\end{array}$ & 0.41 \\
\hline Small for gestational age & $3(9 \%)$ & $1(11 \%)$ & 0.98 \\
\hline Antenatal steroid therapy & $30(88 \%)$ & $8(89 \%)$ & 0.98 \\
\hline Surfactant therapy & $10(29 \%)$ & $5(56 \%)$ & 0.24 \\
\hline Culture proven early-onset neonatal sepsis & $0(0 \%)$ & $0(0 \%)$ & 1.0 \\
\hline Caffeine therapy & $33(97 \%)$ & $9(100 \%)$ & 0.98 \\
\hline Postnatal age at extubation (days) & $13(10.5-15.5)$ & $16(14.5-17)$ & 0.02 \\
\hline Body weight at extubation (g) & $1177 \pm 245$ & $1047 \pm 146$ & 0.1 \\
\hline $\begin{array}{l}\text { Duration of invasive mechanical ventilation } \\
\text { (days) }\end{array}$ & $6.5(4-9)$ & $10(7.5-11.5)$ & 0.04 \\
\hline $\begin{array}{l}\text { Pre-extubation mean airway pressure }(\mathrm{cm} \\
\left.\mathrm{H}_{2} \mathrm{O}\right)\end{array}$ & $6.3 \pm 0.5$ & $6.6 \pm 0.3$ & 0.03 \\
\hline $\begin{array}{l}\text { Pre-extubation fraction of inspired oxygen } \\
\quad\left(\mathrm{FiO}_{2}\right)\end{array}$ & $21.1 \pm 0.6$ & $23.6 \pm 2.0$ & $<0.001$ \\
\hline
\end{tabular}

Data expressed as mean $\pm \mathrm{SD}$, median (inter-quartile range), or number (percentage) 
Table 2 Sonographic diaphragmatic parameters of the studied groups

\begin{tabular}{|c|c|c|c|}
\hline Characteristics & $\begin{array}{l}\text { Successful extubation group } \\
(n=34)\end{array}$ & $\begin{array}{l}\text { Failed extubation group } \\
(n=9)\end{array}$ & $p$ value \\
\hline $\begin{array}{l}\text { Inspiratory thickness of the right } \\
\text { hemidiaphragm }(\mathrm{mm})\end{array}$ & $1.38 \pm 0.10$ & $1.32 \pm 0.07$ & 0.07 \\
\hline $\begin{array}{l}\text { Expiratory thickness of the right } \\
\text { hemidiaphragm (mm) }\end{array}$ & $1.29 \pm 0.13$ & $1.19 \pm 0.04$ & 0.02 \\
\hline $\begin{array}{l}\text { Excursion of the right } \\
\text { hemidiaphragm }(\mathrm{mm})\end{array}$ & $3.43 \pm 0.41$ & $2.37 \pm 0.37$ & $<0.001$ \\
\hline $\begin{array}{l}\text { Inspiratory thickness of the left } \\
\text { hemidiaphragm (mm) }\end{array}$ & $1.35 \pm 0.14$ & $1.23 \pm 0.14$ & 0.03 \\
\hline $\begin{array}{l}\text { Expiratory thickness of the left } \\
\text { hemidiaphragm }(\mathrm{mm})\end{array}$ & $1.24 \pm 0.10$ & $1.16 \pm 0.07$ & 0.03 \\
\hline $\begin{array}{l}\text { Excursion of the left } \\
\text { hemidiaphragm }(\mathrm{mm})\end{array}$ & $3.08 \pm 0.36$ & $2.0 \pm 0.53$ & $<0.001$ \\
\hline $\begin{array}{l}\text { Diaphragm thickening fraction (DTF) of the } \\
\text { right hemidiaphragm }(\%)\end{array}$ & $38.4 \pm 9.4$ & $32.1 \pm 7.5$ & 0.07 \\
\hline $\begin{array}{l}\text { Diaphragm thickening fraction (DTF) of the } \\
\text { left hemidiaphragm }(\%)\end{array}$ & $35.4 \pm 14.2$ & $23.3 \pm 15.1$ & 0.03 \\
\hline
\end{tabular}

Data expressed as mean $\pm \mathrm{SD}$

to 28 weeks gestation, $4.8 \pm 0.2 \mathrm{~mm}$ in 29 to 31 weeks gestation, $4.6 \pm 0.2 \mathrm{~mm}$ in 32 to 34 weeks gestation, and $4.4 \pm$ $0.3 \mathrm{~mm}$ in 35 to 37 weeks gestation [22]. The difference between our measurements and Rehan's study is attributed to their inclusion of clinically stable preterm infants who have no evidence of any acute illness, no culture proven sepsis, not on

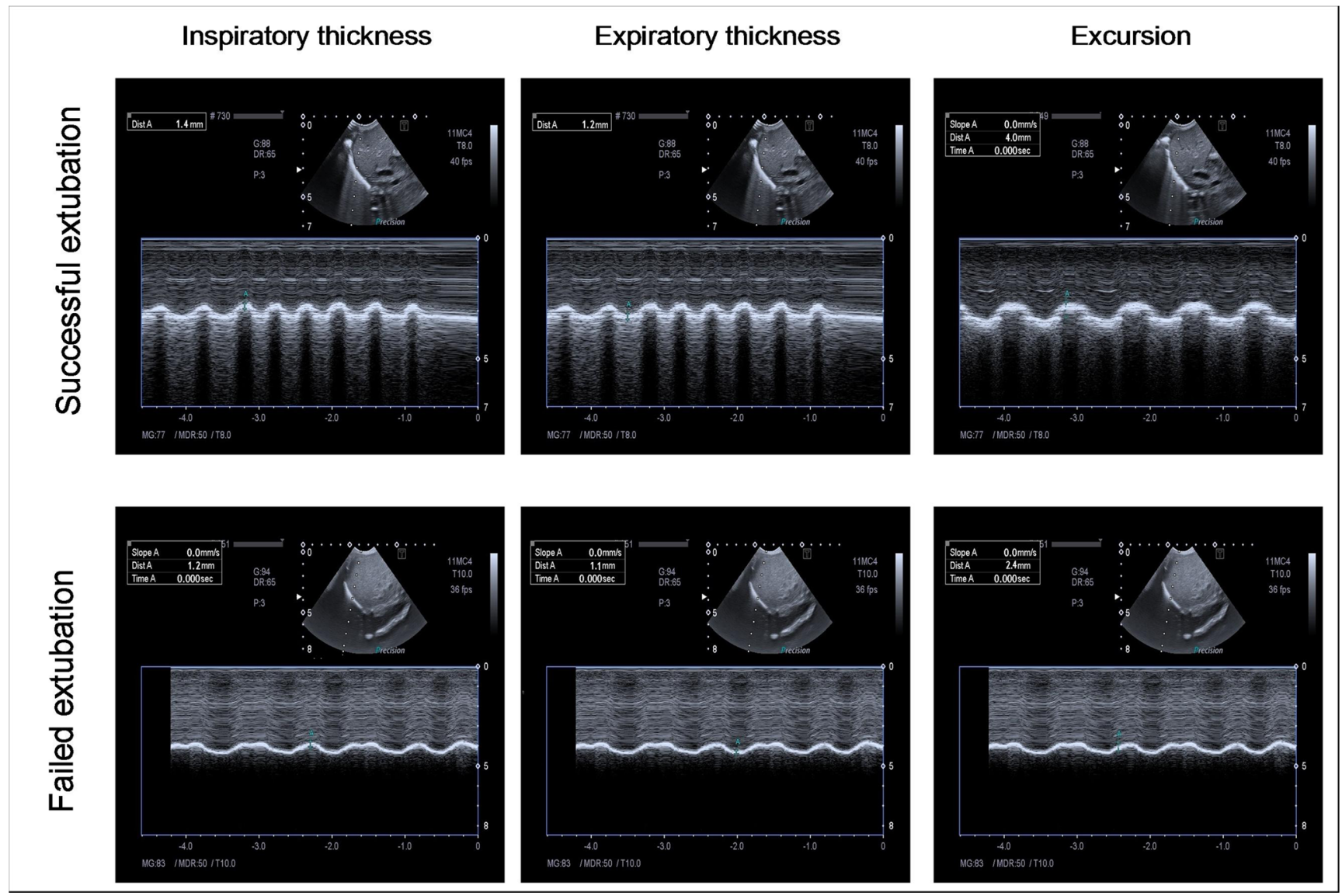

Fig. 2 Sonographic images showing M-mode measurements of inspiratory thickness, expiratory thickness, and excursion of the right hemidiaphragm in an infant (case number 5) from the successful extubation group and an infant (case number 11) from the failed extubation group 
Table 3 Correlation between duration of pre-extubation (invasive) mechanical ventilation and sonographic diaphragmatic parameters of the studied groups

\begin{tabular}{llc}
\hline Characteristics & $\begin{array}{l}\text { All infants } \\
(n=43)\end{array}$ \\
\cline { 2 - 3 } & $r$ & $p$ value \\
\hline Inspiratory thickness of the right hemidiaphragm (mm) & -0.63 & $<0.001$ \\
Expiratory thickness of the right hemidiaphragm (mm) & -0.58 & $<0.001$ \\
Excursion of the right hemidiaphragm (mm) & -0.31 & 0.04 \\
Inspiratory thickness of the left hemidiaphragm (mm) & -0.64 & $<0.001$ \\
Expiratory thickness of the left hemidiaphragm (mm) & -0.53 & $<0.001$ \\
Excursion of the left hemidiaphragm (mm) & -0.25 & 0.09 \\
Diaphragm thickening fraction (DTF) of the right hemidiaphragm $(\%)$ & -0.61 & $<0.001$ \\
Diaphragm thickening fraction (DTF) of the left hemidiaphragm (\%) & -0.64 & $<0.001$ \\
\hline
\end{tabular}

any oxygen supplementation, and not on CPAP or ventilator support compared with our ventilated infants. Radicioni and colleagues tested the accuracy of a model that consists of the sonographic measurements of right diaphragmatic excursions during inspiration and expiratory phases plus the oxygen saturation $/ \mathrm{FiO}_{2}$ ratio as a predictor for CPAP failure in preterm infants with respiratory distress syndrome. The authors found that integration of both measures in this model has a high accuracy, with AUC 0.95, in predicting CPAP failure [19].

In mechanically ventilated adults, sonographic assessment of diaphragmatic function showed that diaphragmatic excursion was significantly higher in the successful group compared with those who failed extubation [6]. Liu and colleagues found that diaphragmatic excursion had a sensitivity of $89.2 \%$ and a specificity of $75.0 \%$ with an AUC (ROC) of 0.849 in predicting successful extubation in mechanically ventilated adult patients. The cut-off value of diaphragmatic excursion for predicting successful extubation was determined to be $1.14 \mathrm{~cm}$ by ROC curve analysis [16]. Yoo et al. found that diaphragmatic excursion is more accurate than a change in the diaphragm thickness to predict extubation success in mechanically ventilated adults [31]. In a metaanalysis of 13 studies over 742 adults, Li and colleagues concluded that diaphragmatic excursion and thickness are accurate measures for predicting reintubation within $48 \mathrm{~h}$ of extubation despite having a large heterogeneities among the included studies [15].

In mechanically ventilated adults, McCool and colleagues [17] showed that the duration of mechanical ventilation was significantly shorter in patients diagnosed with normal diaphragmatic function as assessed by ultrasound measurement of diaphragmatic thickness and excursion. The authors stated that normal diaphragmatic function as assessed by ultrasound shows $90.9 \%$ sensitivity, $86.7 \%$ specificity, $90.9 \%$ positive predictive value, and $86.7 \%$ negative predictive value in predicting successful extubation from mechanical ventilation [17].
The proposed mechanism for diaphragmatic dysfunction in association with invasive mechanical ventilation is the loss of myofilament protein of diaphragmatic muscle which results in what is known as ventilator-induced diaphragmatic dysfunction (VIDD). A previous research revealed that only 18-24 h of invasive mechanical ventilation is sufficient to develop VIDD in both laboratory animals and humans [18]. In animal models, ventilator-induced diaphragmatic proteolysis and associated diaphragmatic atrophy occur due to increased diaphragmatic protein breakdown and decreased protein synthesis which is mediated by various proteases, such as calpain, caspase-3, autophagy, and the ubiquitin-proteasome system [18]. We have found that expiratory thickness of the right and left hemidiaphragm and inspiratory thickness of the left hemidiaphragm were significantly lower in infants who failed compared with infants who succeeded extubation from mechanical ventilation. Our results support previous results of ventilator-induced diaphragmatic atrophy which were retrieved by animal studies and human studies $[11,14]$. This is further supported by our finding of negative correlation between the duration of mechanical ventilation with inspiratory and expiratory thickness of the right and left hemidiaphragm, excursion of the right hemidiaphragm, and DTF of the right and left hemidiaphragm. The possible cause of the absence of significant difference in the inspiratory thickness and thickening fraction of the right hemidiaphragm between successfully and failed extubated preterm infants can be attributed to the supporting effect of the liver to the right hemidiaphragm during inspiration which can mask minimal effects on the muscle mass of the right hemidiaphragm. Another possibility for this non-significant difference may be related to our use of $\mathrm{M}$ mode technique during measurement. Compared with Bmode, M-mode may not obtain reliable measurements of the diaphragmatic thickness, due to the subtlety of the imaging line. However, we compensated for this by obtaining our Mmode measures over the most moving point of the hemidiaphragm on B-mode. Moreover, M-mode technique 
a

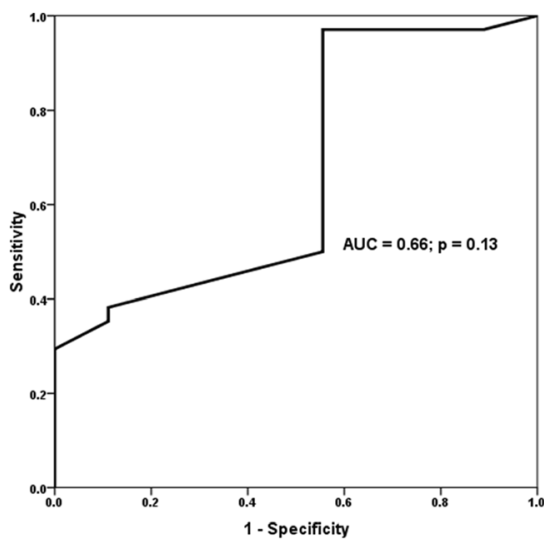

d

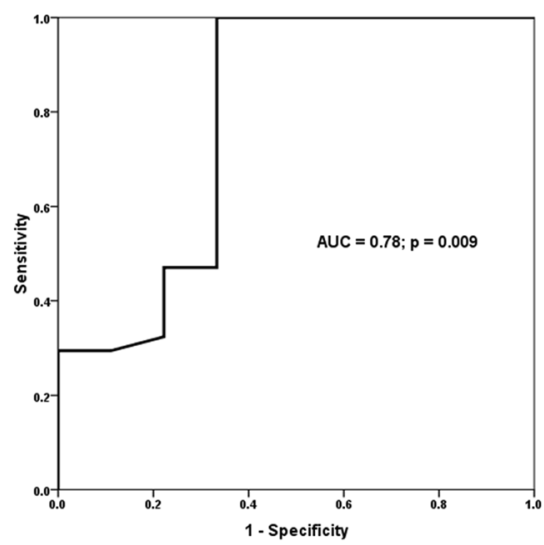

g

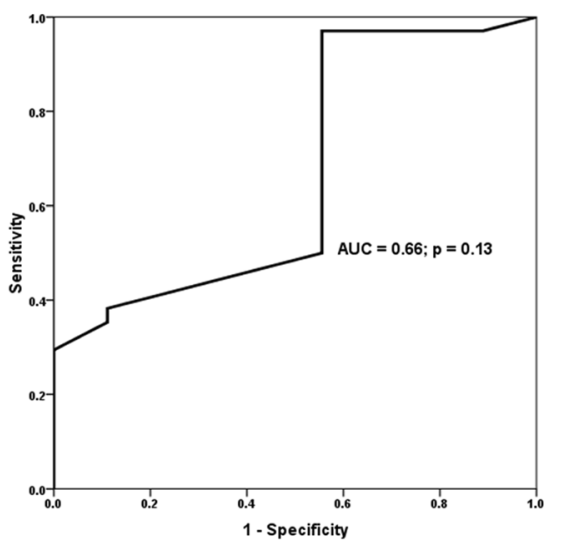

b

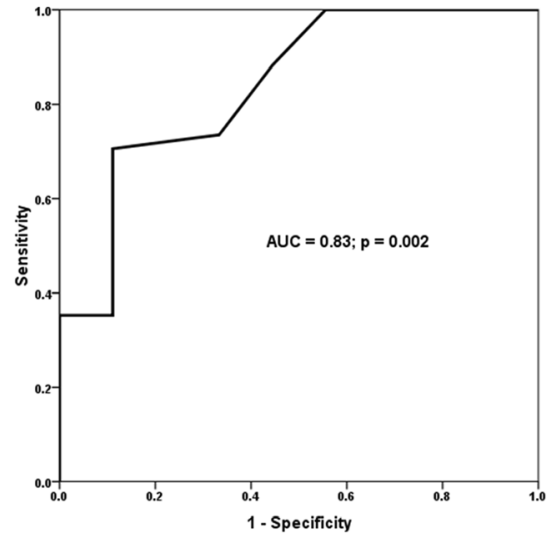

e

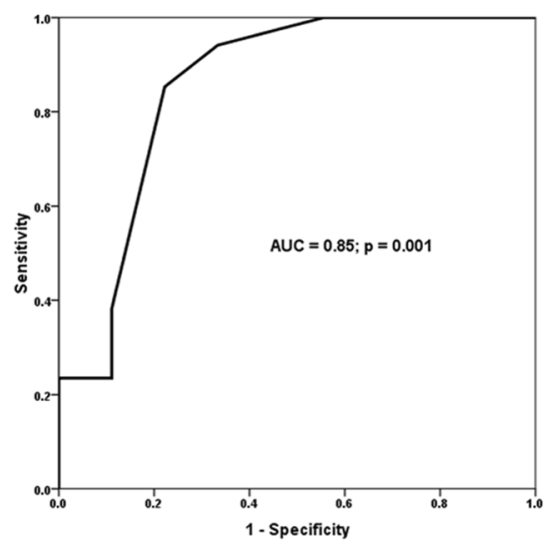

h

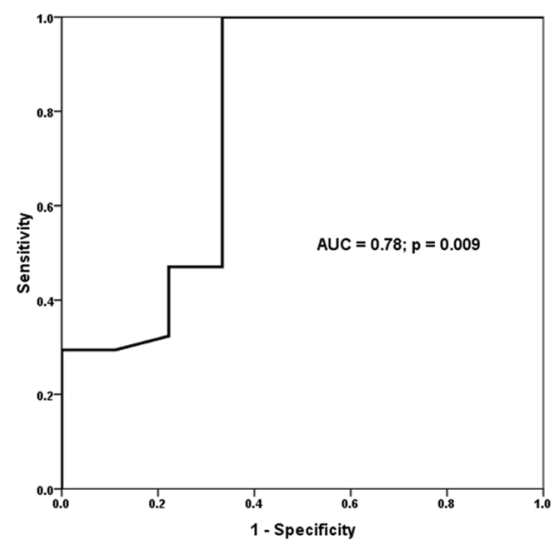

C

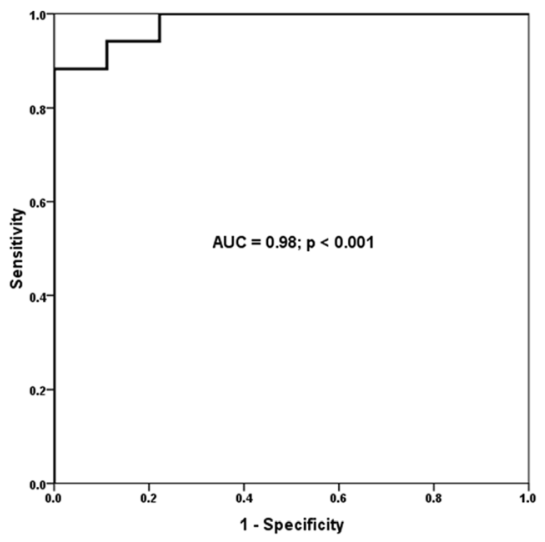

f

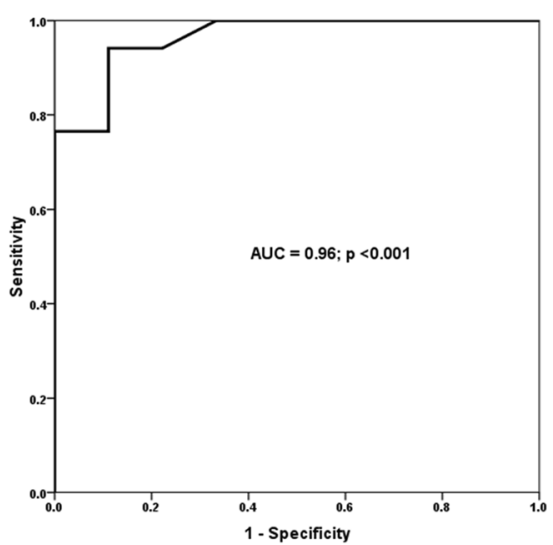

Fig. 3 Receiver-operating characteristic curves show area under the curve (AUC) and $p$ value of significance for inspiratory thickness of the right hemidiaphragm (a), expiratory thickness of the right hemidiaphragm (b), excursion of the right hemidiaphragm (c), inspiratory thickness of the left hemidiaphragm (d), expiratory thickness of the left

hemidiaphragm (e), excursion of the left hemidiaphragm (f), and diaphragm thickening fraction (DTF) of the right hemidiaphragm (g) and the left hemidiaphragm (h) in predicting successful extubation of preterm infants from mechanical ventilation

has been successfully used in previous studies to measure diaphragmatic thickness in excursion in adults and pediatric age groups $[9,30]$.

A potential technical limitation to our study is the use of a micro-convex transducer rather than a high-frequency microlinear transducer for imaging. The latter has better ability for

visualization of the thin muscles and superficial structures, like hemidiaphragm. However, the micro-convex transducer gives a better in-between ribs view and wider angle of image "pie-shaped image" of the whole hemidiaphragm which allows for better identification of the most moving part of the hemidiaphragm in B-mode. We compensated for this 
technical limitation by taking our M-mode measurements at the most moving part of hemidiaphragm in the B-mode view.

We acknowledge that the study is limited by the relatively small sample size, which is attributed to our adoption of the early administration of non-invasive respiratory support techniques to our preterm infants to minimize ventilator-induced lung injury which decreased the percentage of preterm infants who required invasive mechanical ventilation during the study period. The study is also limited by the lack of physiopathologic proof of respiratory etiology as a cause for extubation failure and the need for reintubation. It is of note that assessment of diaphragmatic function in infants who failed extubation due to non-respiratory causes, such as central apnea or poor respiratory drive, is less valuable. Moreover, our practice of extubation to a nasal CPAP of $5 \mathrm{~cm} \mathrm{H}_{2} \mathrm{O}$ represents another limitation given the new guidelines of extubating preterm infants to CPAP pressure of 7-9 $\mathrm{cm} \mathrm{H}_{2} \mathrm{O}$ [25]. Our low level of CPAP support may have resulted to an increased incidence of preterm infants who required reintubation. Future studies should consider evaluation of diaphragmatic thickness and excursion in relation of different modes and parameters of respiratory support to find out the appropriate approach for respiratory support in preterm infants that maintain adequate diaphragmatic stimulation and prevent VIDD.

In conclusion, sonographic assessment of diaphragmatic thickness and excursion represents a promising sensitive and specific easily applicable tool to predict successful extubation of preterm infants from invasive conventional mechanical ventilation.

Authors' contributions Eslam Bahgat and Hanan El-Halaby participated in the design of the study, data collection, and writing the manuscript. Ashraf Abdelrahman participated in sonographic assessment of the diaphragm and manuscript writing. Nehad Nasef and Hesham Abdel-Hady participated in formulating the hypothesis, design of the study, data collection, data interpretation, statistical analysis, and writing of the manuscript. All authors approved the final manuscript as submitted and agree to be accountable for all aspects of the work.

\section{Compliance with ethical statements}

Conflict of interests The authors declare that they have no conflict of interest.

Ethical approval This article has been approved by the Institutional Review Board (IRB), Mansoura Faculty of Medicine, Mansoura, Egypt.

Informed consent Informed consent was obtained from all individual participants included in the study.

\section{References}

1. Bhat RY, Greenough A, Rafferty GF, Patel S, Chandler C (2004) Assessment of diaphragm function in lumbocostovertebral syndrome. Eur J Pediatr 163:694-695
2. Buonsenso D, Musolino A (2018) Point of care diaphragm ultrasound in infants with bronchiolitis. Pediatr Pulmonol 53:1597

3. Dimitriou G, Greenough A, Endo A, Cherian S, Rafferty GF (2002) Prediction of extubation failure in preterm infants. Arch Dis Child Fetal Neonatal Ed 86:F32-F35

4. DiNino E, Gartman EJ, Sethi JM, McCool FD (2013) Diaphragm ultrasound as a predictor of successful extubation from mechanical ventilation. Thorax 69:423-427

5. El-Halaby H, Abdel-Hady H, Alsawah G, Abdelrahman A, ElTahan H (2016) Sonographic evaluation of diaphragmatic excursion and thickness in healthy infants and children. J Ultrasound Med 35:167-175

6. Farghaly S, Hasan AA (2017) Diaphragm ultrasound as a new method to predict extubation outcome in mechanically ventilated patients. Aust Crit Care 30:37-43

7. Fox WW, Schwartz JG, Shaffer TH (1981) Successful extubation of neonates: clinical and physiological factors. Crit Care Med 9: 823-826

8. Goligher EC, Laghi F, Detsky ME, Farias P, Murray A, Brace D, Brochard LJ, Bolz SS, Rubenfeld GD, Kavanagh BP, Ferguson ND (2015) Measuring diaphragm thickness with ultrasound in mechanically ventilated patients: feasibility, reproducibility and validity. Intensive Care Med 41:734

9. Huang D, Ma H, Zhong W, Wang X, Wu Y, Qin T, Wang S, Tan N (2017) Using M-mode ultrasonography to assess diaphragm dysfunction and predict the success of mechanical ventilation weaning in elderly patients. J Thorac Dis 9:3177-3186

10. Hussain SN, Cornachione AS, Guichon C, Al Khunaizi A, Leite Fde S, Petrof BJ, Mofarrahi M, Moroz N, de Varennes B, Goldberg P, Rassier DE (2016) Prolonged controlled mechanical ventilation in humans triggers myofibrillar contractile dysfunction and myofilament protein loss in the diaphragm. Thorax 71:436-445

11. Jaber S, Jung B, Matecki S, Petrof BJ (2011) Clinical review: ventilator-induced diaphragmatic dysfunction-human studies confirm animal model findings! Crit Care 15:206

12. Kamlin CO, Davis PG, Morley CJ (2006) Predicting successful extubation of very low birthweight infants. Arch Dis Child Fetal Neonatal Ed 91:F180-F183

13. Kantarci F, Mihmanli I, Demirel MK, Harmanci K, Akman C, Aydogan F, Mihmanli A, Uysal O (2004) Normal diaphragmatic motion and the effects of body composition: determination with Mmode sonography. J Ultrasound Med 23:255-260

14. Lee EP, Hsia SH, Hsiao HF, Chen MC, Lin JJ, Chan OW, Lin CY, Yang MC, Liao SL, Lai SH (2017) Evaluation of diaphragmatic function in mechanically ventilated children: an ultrasound study. PLoS One 12:e0183560

15. Li C, Li X, Han H, Cui H, Wang G, Wang Z (2018) Diaphragmatic ultrasonography for predicting ventilator weaning: a meta-analysis. Medicine (Baltimore) 97:e10968

16. Liu LX, Su D, Hu ZJ (2017) The value of the excursion of diaphragm tested by ultrosonography to predict weaning from mechanical ventilation in ICU patients. Zhonghua Nei Ke Za Zhi 56: 495-499

17. McCool FD, Oyieng'o DO, Koo P (2020) The utility of diaphragm ultrasound in reducing time to extubation. Lung 198:499-505

18. Powers SK, Wiggs MP, Sollanek KJ, Smuder AJ (2013) Ventilatorinduced diaphragm dysfunction: cause and effect. Am J Physiol Regul Integr Comp Physiol 305:R464-R477

19. Radicioni M, Leonardi A, Lanciotti L, Rinaldi VE, Bini V, Camerini PG (2020) How to improve CPAP failure prediction in preterm infants with RDS: a pilot study. Eur J Pediatr: [published online ahead of print, 2020 Jun 19]. Eur J Pediatr. https://doi.org/ 10.1007/s00431-020-03700-w

20. Rafferty GF, Greenough A, Dimitriou G, Kavadia V, Laubscher B, Polkey MI, Harris ML, Moxham J (2000) Assessment of neonatal 
diaphragm function using magnetic stimulation of the phrenic nerves. Am J Respir Crit Care Med 162:2337-2340

21. Rehan VK, Laiprasert J, Nakashima JM, Wallach M, McCool FD (2001) Effects of continuous positive airway pressure on diaphragm dimensions in preterm infants. J Perinatol 21:521-524

22. Rehan VK, Laiprasert J, Wallach M, Rubin LP, McCool FD (2001) Diaphragm dimensions of the healthy preterm infant. Pediatrics 108:E91

23. Shaffer TH, Wolfson MR, Bhutani VK (1981) Respiratory muscle function, assessment, and training. Phys Ther 61:1711-1723

24. Singh Y, Tissot C, Fraga MV, Yousef N, Cortes RG, Lopez J, Sanchez-de-Toledo J, Brierley J, Colunga JM, Raffaj D, Da Cruz E, Durand P, Kenderessy P, Lang HJ, Nishisaki A, Kneyber MC, Tissieres P, Conlon TW, De Luca D (2020) International evidencebased guidelines on Point of Care Ultrasound (POCUS) for critically ill neonates and children issued by the POCUS Working Group of the European Society of Paediatric and Neonatal Intensive Care (ESPNIC). Crit Care 24:65

25. Sweet DG, Carnielli V, Greisen G, Hallman M, Ozek E, Te Pas A, Plavka R, Roehr CC, Saugstad OD, Simeoni U, Speer CP, Vento M, Visser GHA, Halliday HL (2019) European consensus guidelines on the management of respiratory distress syndrome-2019 update. Neonatology 115:432-450
26. Tapia-Rombo CA, Galindo-Alvarado AM, Saucedo-Zavala VJ, Cuevas-Uriostegui ML (2007) Predictive factors of failure extubation among preterm infants. Gac Med Mex 143:101-108

27. Vassilakopoulos T, Petrof BJ (2004) Ventilator-induced diaphragmatic dysfunction. Am J Respir Crit Care Med 169:336-341

28. von Merkel J, Gebauer C, Blaser A, Pulzer F, Thome U, Knupfer M (2012) Prediction of extubation failure in ELBW preterm infants. Klin Padiatr 224:324-330

29. Wolf GK, Walsh BK, Green ML, Arnold JH (2011) Electrical activity of the diaphragm during extubation readiness testing in critically ill children. Pediatr Crit Care Med 12:e220-e224

30. Xue Y, Zhang Z, Sheng CQ, Li YM, Jia FY (2019) The predictive value of diaphragm ultrasound for weaning outcomes in critically ill children. BMC Pulm Med 19:270

31. Yoo JW, Lee SJ, Lee JD, Kim HC (2018) Comparison of clinical utility between diaphragm excursion and thickening change using ultrasonography to predict extubation success. Korean J Intern Med $33: 331-339$

Publisher's note Springer Nature remains neutral with regard to jurisdictional claims in published maps and institutional affiliations. 